\section{Cureus}

\title{
HHV-6 Infection in an Immunocompetent Patient with Multi-organ Failure
}

Richard N. Wang ${ }^{1}$, Radhames Ramos De Oleo ${ }^{2}$, Sushilkumar S. Gupta ${ }^{2}$, Domingo Y. Ynoa Garcia $^{3}$, Yizhak Kupfer ${ }^{2}$

1. Emergency Medicine, Maimonides Medical Center, Brooklyn, USA 2. Critical Care, Maimonides Medical Center, Brooklyn, USA 3. Cardiology, Cardiology Unlimited, New York, USA

$\square$ Corresponding author: Radhames Ramos De Oleo, radhamesramos73@gmail.com Disclosures can be found in Additional Information at the end of the article

\section{Abstract}

Human herpesvirus 6 (HHV-6) is a double-stranded DNA virus part of the Herpesviridae family that colonizes nearly $100 \%$ of the human population. The virus is known to be the etiologic agent of roseola infantum, a self-limited disease in childhood and reactivation of the virus later in life is linked to potentially severe manifestations, including encephalitis, in immunosuppressed patients. It is rare in immunocompetent patients, but there have been several reports of encephalitis due to HHV-6 reactivation. We describe here a case of altered mental status and multi-organ failure in an immunocompetent woman, whose cerebrospinal fluid (CSF) was positive for HHV-6 DNA by polymerase chain reaction (PCR).

Categories: Infectious Disease, Internal Medicine

Keywords: hhv-6, encephalitis, immunocompetent

\section{Introduction}

Human herpesvirus 6 (HHV-6) is a double-stranded DNA virus part of the Herpesviridae family. All herpesviruses can establish a lifelong latent infection after the viral genome integrates into host cell DNA. HHV-6 colonizes nearly $100 \%$ of the human population [1]. The virus is known to be the etiologic agent of roseola infantum, a self-limited disease in childhood. Reactivation of the virus later in life is linked to potentially severe manifestations, including encephalitis, in immunosuppressed patients, such as after hematopoietic stem cell transplant [2]. It's occurance is rare in immunocompetent patients, but there have been several reports of encephalitis due to HHV-6 reactivation [3]. We report the case of altered mental status and multi-organ failure in an immunocompetent woman, whose cerebrospinal fluid (CSF) was positive for HHV-6 DNA by polymerase chain reaction (PCR).

Received 06/20/2019

Review began 06/25/2019

Review ended 08/19/2019

Published 08/24/2019

\section{(c) Copyright 2019}

Wang et al. This is an open access article distributed under the terms of the Creative Commons Attribution License CC-BY 3.0., which permits unrestricted use, distribution, and reproduction in any medium, provided the original author and source are credited.

\section{Case Presentation}

A 93-year-old woman with history of hypertension, diabetes mellitus, coronary artery disease, and atrial fibrillation presented with fever, altered mental status, and reported seizure-like activity. She was, at baseline, able to ambulate with a walker. She had been seen the previous day at an outside hospital for a mechanical fall, with negative computed tomography (CT) scan of the head. The patient was discharged early in the morning and later that morning was unable to be woken up, with the family noting seizure-like activity. She was subsequently brought to the emergency department.

The patient was febrile (temperature 100.4), tachycardic (heart rate between 90-110s), hypoxic 
(peripheral oxygen saturation $88 \%$ on 2 liter nasal cannula), and noted to have a left-sided paresis on physical exam. Her initial National Institute of Health (NIH) Stroke Scale score was 24. Laboratory results were significant for creatinine (1.7 mg/dl; unknown baseline), troponin $(3.21 \mathrm{ng} / \mathrm{ml})$, and lactic acid $(4.7 \mathrm{mmol} / \mathrm{L})$. Non-contrast CT of the head was negative. CT scan showed bilateral lobar pneumonia, dilated esophagus with a debris level (but not distal stricture that would point towards achalasia), and asymmetric opacification of the middle cerebral artery branches without corresponding asymmetry on CT perfusion. She was deemed not a candidate for tissue plasminogen activator or endovascular revascularization.

The patient was intubated for airway protection and admitted to the medical intensive care unit for altered mental status, cerebrovascular accident (CVA), non-ST elevation myocardial infarction (NSTEMI), and respiratory failure secondary to bilateral aspiration pneumonia. She was started on aspirin, high intensity atorvastatin and minocycline for CVA, levetiracetam for seizure prophylaxis, and intravenous vancomycin, ceftriaxone, metronidazole and ampicillin for broad coverage given possible meningitis as well as aspiration pneumonia. An EEG was performed with no evidence of seizure activity. A lumbar puncture was performed by interventional radiology on day five of admission and revealed in the CSF 14 white blood cells/ $\mu \mathrm{l}$ (86\% lymphocytes, 14\% neutrophils), $155 \mathrm{red}$ blood cells/ $\mu \mathrm{l}$, glucose $82 \mathrm{mg} / \mathrm{dl}$, and protein $50 \mathrm{mg} / \mathrm{dl}$; no opening pressure was documented. HHV-6 DNA was detected in the CSF, viral load was 395 copies per ml. A Magnetic Resonance Imaging (MRI) was never performed. Given the patient's gradually improving mental status, antiviral treatment was deferred. The patient was extubated on day ten of admission and transferred to the medical floor, where she was ultimately discharged to hospice care per the family’s wishes.

\section{Discussion}

HHV-6 is well known to cause roseola infantum and clinical manifestations in immunosuppressed patients, in particular after hematopoietic stem cell transplant. However, HHV-6 meningoencephalitis in immunocompetent patients is rare, although there are increasing numbers of reported cases. The presumed pathogenesis is reactivation of the virus. It has been established that HHV-6 has a tropism for central nervous system tissues [4]. One study retrospectively analyzed samples from patients with HHV-6 by PCR from various tissues, including blood, CSF, ascites, and tissue biopsy [5]. Three types of clinical entities were identified: neurological manifestations, including convulsions and encephalitis in nonimmunocompromised patients, digestive problems in immunosuppressed patients, and severe maternal-fetal infection. The encephalitis may potentially present as status epilepticus [6].

The significance of HHV-6 in the CSF has been debated. It is difficult to distinguish between latent and active viral infection. The high CSF viral load supports the possibility of HHV-6 as the etiologic agent of disease in the case series by Isaacson et al [7]. There is increased levels of HHV-6 IgG and IgM in a subset of encephalitis patients compared with other neurological diseases [8]. On the other hand, HHV-6 has been detected in brain tissue specimens of healthy patients with no evidence of neurological disease [9]. In addition, reports of HHV-6 encephalitis have had differing findings on neuroimaging, illness severity and outcome, and hospital course [3]. However, this may be explained by viral genome variations and host genetics. In our case, we might debate that the patient had other causes for the alteration in her mental status but despite this, we cannot ignore the high viral load of HHV-6 in the CSF. The other conditions that the patient had that could have altered her mental were not as definitive as to explain her profound delirium, only the active infection of a neurotropic virus could explain such findings

There are currently no therapies approved for treatment. Small studies and case reports describe success with drugs such as cidofovir, ganciclovir, foscarnet, and new small molecule inhibitors are being developed [10]. For example, there was a significant decrease in viral load 
after treatment with ganciclovir. However, there is a lack of definitive cause and effect relationship between HHV-6 reactivation and disease that requires intervention. In addition, the efficacy of ganciclovir and other compounds may not be optimal and is linked to toxicity. Valganciclovir has been successful and suggested as a potential practical outpatient treatment [10]. In our patient or any other patient, even if other conditions that can explain acute changes in mental status, it is important to maintain neurological infections with HHV-6 in our list of differential diagnoses

\section{Conclusions}

We believe this case report will help physicians to consider HHV infection early in the list of differentials of altered mental status and in the management of this patient. Even if the HHV-6 virus is a co-condition and other conditions in the patient could explain alteration in sensorium, we should keep this virus as a differential.

\section{Additional Information \\ Disclosures}

Human subjects: Consent was obtained by all participants in this study. Conflicts of interest: In compliance with the ICMJE uniform disclosure form, all authors declare the following: Payment/services info: All authors have declared that no financial support was received from any organization for the submitted work. Financial relationships: All authors have declared that they have no financial relationships at present or within the previous three years with any organizations that might have an interest in the submitted work. Other relationships: All authors have declared that there are no other relationships or activities that could appear to have influenced the submitted work.

\section{References}

1. Jaworska J, Gravel A, Flamand L: Divergent susceptibilities of human herpesvirus 6 variants to type I interferons. Proc Natl Acad Sci U S A. 2010, 107:8369-8374. 10.1073/pnas.0909951107

2. Gewurz BE, Marty FM, Baden LR, Katz JT: Human herpesvirus 6 encephalitis . Curr Infect Dis Rep. 2008, 10:292-299.

3. Trabue CH, Bloch KC, Myers JW, Moorman JP: Case report and literature review: HHV-6associated meningoencephalitis in an immunocompetent adult. Herpes J IHMF. 2008, 15:3335.

4. Braun DK, Dominguez G, Pellett PE: Human herpesvirus 6. Clin Microbiol Rev. 1997, 10:521567.

5. Revest M, Minjolle S, Veyer D, Lagathu G, Michelet C, Colimon R: Detection of HHV-6 in over a thousand samples: New types of infection revealed by an analysis of positive results. J Clin Virol. 2011, 51:20-24. 10.1016/j.jcv.2011.02.001

6. Shahani L: HHV-6 encephalitis presenting as status epilepticus in an immunocompetent patient. BMJ Case Rep. 2014, 2014: 10.1136/bcr-2014-205880

7. Isaacson E, Glaser CA, Forghani B, et al.: Evidence of Human Herpesvirus 6 Infection in 4 Immunocompetent Patients with Encephalitis. Clin Infect Dis. 2005, 40:890-893. $10.1086 / 427944$

8. Yao K, Honarmand S, Espinosa A, Akhyani N, Glaser C, Jacobson S: Detection of human herpesvirus-6 in cerebrospinal fluid of patients with encephalitis. Ann Neurol. 2009, 65:257267. 10.1002/ana.21611

9. Cuomo L, Trivedi P, Cardillo MR, et al.: Human herpesvirus 6 infection in neoplastic and normal brain tissue. J Med Virol. 2001, 63:45-51.

10. Righi E, Carnelutti A, Muser D, et al.: Successful treatment and FDG-PET/CT monitoring of HHV-6 encephalitis in a non-neutropenic patient: case report and literature review. J Neurovirol. August. 2017, 10.1007/s13365-017-0566-4 